\title{
Investigating the Efficacy of Triple Drug Therapy and Sequential Drug Therapy in the Eradication of Helicobacter Pylori with Respect to Antigen Stool test: A Pilot Study Shrestha R, ${ }^{1,2}$ Poudel R, ${ }^{3}$ Shakya $S,{ }^{1}$ Gurung RB, ${ }^{4}$ Makaju R, ${ }^{5}$ Koju P ${ }^{2}$
}

\author{
${ }^{1}$ Department of Pharmacology, \\ ${ }^{2}$ Pharmacovigillance Unit/ Research \& Development \\ Division, \\ Dhulikhel Hospital, Kathmandu University Hospital, \\ Dhulikhel, Kavre. \\ ${ }^{3}$ Department of Pharmacology, Nepal Medical \\ College, Jorpati, Kathmandu. \\ ${ }^{4}$ Department of Internal Medicine, \\ ${ }^{5}$ Department of Pathology, \\ Kathmandu University School of Medical Sciences, \\ Dhulikhel Hospital, Kathmandu University Hospital, \\ Dhulikhel, Kavre.
}

\section{Corresponding Author}

Rajeev Shrestha

Department of Pharmacology,

Dhulikhel Hospital, Kathmandu University Hospital,

Dhulikhel, Kavre.

E-mail: rmaleku@hotmail.com

\section{Citation}

Shrestha R, Poudel R, Shakya S, Gurung RB, Makaju $R$, Koju P. Investigating the Efficacy of Triple Drug Therapy and Sequential Drug Therapy in the Eradication of Helicobacter pylori with Respect to Antigen Stool test: A Pilot Study. Kathmandu Univ Med J. 2020;69(1):74-83.

\section{ABSTRACT}

\section{Background}

Helicobacter pylori is one of the most prevalent infectious disease worldwide. The treatment regimens involve mainly two therapies: Standard Triple drug therapy and Sequential drug therapy. Several studies have shown that the sequential therapy has higher eradication rates of $\mathrm{H}$. pylori than the standard triple drug therapy and since proper study on sequential drug therapy and standard triple drug therapy is still lacking in Nepal, this study is attempted to compare efficacy of Sequential Drug Therapy in the eradication of $H$. pylori in gastritis with respect to the Standard triple drug therapy.

\section{Objective}

To investigate the efficacy of Triple Drug Therapy and Sequential Drug Therapy in the eradication of Helicobacter pylori with respect to Antigen Stool test.

\section{Method}

This study was the prospective study conducted in 62 patients attending the Department of Gastroenterology, Dhulikhel Hospital, meeting the inclusion criteria who were confirmed as $\mathrm{H}$. pylori positive by histopathology and stool antigen test. Patients were randomized into two groups. One group prescribed with Standard triple drug regimen and another group with Sequential drug regimen. Eradication of $H$. pylori infection was confirmed by repeating the stool antigen test at least five weeks after the completion of the regimen.

\section{Result}

Among the 62 participants included in this study, 54.5\% of them were males. Among the study population, the eradication achieved by standard triple drug therapy was $87.8 \%$ and $89.6 \%$ with Sequential drug therapy. Higher numbers $(82.3 \%)$ of patients were compliant to the prescribed medication. Forgetfulness was the main reason for missing the dose $(91 \%)$ of the non-compliant patients.

\section{Conclusion}

The study revealed an equal efficacy of both Standard Triple drug regimen and Sequential drug regimen in the eradication of $H$. pylori infection. Further, Stool antigen test can be preferred as a non-invasive test, for diagnosis of $H$. pylori infection, monitoring the response to treatment and in epidemiological studies.

\section{KEY WORDS}

Helicobacter pylori, Sequential drug therapy, Stool antigen test, Triple drug therapy 


\section{INTRODUCTION}

Helicobacter pylori is one of the most prevalent infectious diseases worldwide, affecting an estimated $40-50 \%$ of the world population. ${ }^{1}$ Worldwide, more than $80 \%$ of duodenal ulcers and more than $60 \%$ of gastric ulcers are associated with $H$. pylori. ${ }^{2}$ The prevalence rate seems to be higher in developing countries then in developed countries. ${ }^{3}$ A lack of proper sanitation, safe drinking water and basic hygiene, as well as poor diets and overcrowding, all play role in determining the overall prevalence of infection. ${ }^{4}$

Various drug regimens have been recommended for the initial treatment of $H$. pylori infection. ${ }^{5,6}$ These include conventional triple, quadruple, or sequential therapy regimens. The first-line choice of treatment of $H$. pylori eradication consists of conventional triple drug therapy, which includes a proton pump inhibitor (PPI), Clarithromycin $500 \mathrm{mg}$ and either Amoxicillin 1gm or Metronidazole $500 \mathrm{mg}$ for 7-14 days in the United States and Europe. ${ }^{7,8}$ Triple therapy is used in area where clarithromycin resistance is low $(<15 \%)$. However, when Clarithromycin resistance is high $(>15 \%)$, quadruple therapy is used to treat $H$. pylori. ${ }^{9,10}$ However, during the past few years, the efficacy of conventional triple therapy has decreased, with eradication rates of less than $80 \% .^{11,12}$ Decreased eradication rates are primarily due to increased bacterial resistance to clarithromycin, indicating the need for new first-line treatment. ${ }^{12}$

Among the first line treatment options, sequential therapy regimens have shown higher eradication rates than the conventional triple therapy in several recent

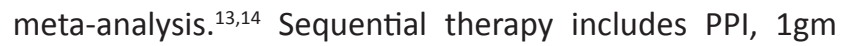
of amoxicillin, each administered twice daily for 5 days, followed by PPI, $500 \mathrm{mg}$ of clarithromycin and $500 \mathrm{mg}$ of tinidazole, each administered twice daily for remaining 5 days. The rationale of sequential therapy is that within the first 5 days of therapy, clarithromycin strains are eliminated by amoxicillin and its remnant strains are then eradicated by the 5 days triple therapy to follow. ${ }^{15}$ Several studies have also shown that the sequential therapy has higher eradication rates of $H$. pylori than the conventional triple drug therapy. ${ }^{16}$

Nevertheless, the failure of eradication of $H$. pylori with various treatment regimens has still remained as a challenging problem. ${ }^{17}$ Though the key factor for the treatment failure is associated with the antibiotic resistance, many other factors like the selection of antibiotics, duration of treatment, combination of new drugs and patient compliance have also been found to be contributing to the treatment failure. ${ }^{17}$ There are several factors affecting the patient's compliance to the treatment regimen which includes, the complex treatment regimen, duration of therapy, burden of the pills and the adverse effects. ${ }^{18}$ Due to complexity of drug regimen for the treatment of $H$. pylori infection, many patients discontinue the therapy which leads to non-compliance to medication. ${ }^{19}$
When there is larger number of pills to be taken daily, there is a high chance of discontinuing the therapy, which also lead to the non-compliance. ${ }^{19}$

To date, proper study on efficacy of sequential drug therapy and standard triple drug therapy in the eradication of $H$. pylori lacks in our setting where the prevalence of $H$. pylori is very high. Thus, this study has been carried out to compare the efficacy of sequential drug therapy in the eradication of $H$. pylori with respect to the standard triple drug therapy using Stool antigen test and the factors affecting the treatment failure with respect to patient compliance.

\section{METHODS}

This study is single centered prospective study carried out from January 2015 to February 2017 in Dhulikhel Hospital, Kathmandu University Hospital, Kavre after acquiring ethical clearance. All patients above 18 years old diagnosed as $H$. pylori infection, by endoscopic biopsy and stool antigen test during the study period were included in this study. Those patients who were positive to $H$. pylori test by two aforementioned methods were included in this study. However, patients who were taking either proton pump inhibitors or antibiotics or both within 2 weeks were excluded from the study as it will be difficult to assess the effectiveness and side-effects of the medicines prescribed to the patients. In addition, patients who were in anticoagulants especially warfarin were also excluded from the current study.

All the participants received detailed written information about the study in advance and signed written informed consent before enrollment in the study. The patients were asked questions about their socio-economic status and their personal history using structured questionnaire which also includes patient compliance factors. In addition, all the eligible patients were diagnosed for $H$. pylori infection using histo-pathological study and stool antigen test. Patients with positive results in two diagnostic methods were randomly categorized into equal two treatment groups each group included 31 patients): Standard Triple drug therapy for 14 days and Sequential drug therapy for 10 days.

H. pylori eradication was assessed at least 5 weeks after the end of completion of the treatment by repeating the stool antigen test. The stool antigen reports were considered as negative and positive according to the standard reference range given by American College of Gastroenterology (ACG): stool antigen value $<0.9 \mathrm{U} / \mathrm{ml}$ as negative, 0.9 to 1.0 $\mathrm{U} / \mathrm{ml}$ as equivocal and $>1.0 \mathrm{U} / \mathrm{Ml}$ as positive. ${ }^{5}$

After reviewing the medical record and asking the structured questionnaire, data was entered in EXCEL (2010). The data entered was then analyzed using statistical package for social sciences (SPSS) software version 22. The 
descriptive analysis was presented as mean ( \pm standard deviation) for quantitative variables and absolute numbers (percentage) for qualitative variables. The Mann-Whitney test for quantitative variables and Pearson's Chi Square test for qualitative variables were used to compare the two groups. P-value $<0.05$ was considered statistically significant.

\section{RESULTS}

Among the 62 patients included in this study, 64.5\% $(n=40)$ of them were males with the mean age was found to be $42.1 \pm 8.6$ years. The prevalence of $H$. pylori infection was found to be more in the age group between 30 to 60 years $(61.3 \%)$ and the majority of the study population $(62.9 \%)$ was literate (Table 1.) while $29 \%$ was manual worker (laborer).

Table 1. Demographic Characteristics ( $\mathbf{N}=62$ )

\begin{tabular}{|l|l|}
\hline Characteristics & No. of Patients (\%) \\
\hline Age & $16(25.8)$ \\
\hline $30-60$ & $38(61.3)$ \\
\hline$>60$ & $8(12.9)$ \\
\hline Mean age (SD) 42.1 ( \pm 8.6) & \\
\hline Gender & \\
\hline Male & $40(64.5)$ \\
\hline Female & $22(35.5)$ \\
\hline Literacy & $39(62.9)$ \\
\hline Literate & $23(37.1)$ \\
\hline Illiterate & $18(29)$ \\
\hline Occupation & $16(25.8)$ \\
\hline Laborer & $15(24.2)$ \\
\hline Unemployed & $7(11.3)$ \\
\hline Service & $6(9.7)$ \\
\hline Student & \\
\hline Businessman & \\
\hline
\end{tabular}

\section{Personal history}

While investigating the personal history of the patients, more than $50 \%$ of the patient found to be smoker (Table 2) out of which $47.1 \%$ of patients has smoked cigarette for more than 20 years. Among smokers, most of them smoked 5 to 10 cigarettes per day $(55.8 \%)$.

Further, more than $50 \%$ were patients have habit of drinking alcohol of which approximately $70 \%$ were found to be social drinker (Table 2). Likewise, in terms of duration of alcohol intake, $49.8 \%$ consumed alcohol for less than 20 years whereas $47.2 \%$ of them had consumed alcohol up to 40 years. All the patients have habit of hand washing with soap and water before food and after defecation. As far as food habit is concerned, $77.4 \%$ patients had habit of eating oily food and $32.3 \%(n=20)$ of them had habit of eating
Table 2. Personal History of the participants ( $N=62$ )

\begin{tabular}{|c|c|}
\hline Characteristics & No. of Patients (\%) \\
\hline \multicolumn{2}{|l|}{ Smoking History } \\
\hline Yes & $34(54.8)$ \\
\hline No & $28(45.1)$ \\
\hline \multicolumn{2}{|c|}{ Duration of Smoking ( $n=34$ ) } \\
\hline$<20$ years & $15(44.1)$ \\
\hline $20-40$ years & $16(47.1)$ \\
\hline$\geq 40$ Years & $3(8.8)$ \\
\hline \multicolumn{2}{|c|}{ Cigarette smoking/day ( $n=34)$} \\
\hline$<5$ & $8(23.6)$ \\
\hline $5-10$ & $19(55.8)$ \\
\hline$\geq 10$ & $7(20.6)$ \\
\hline \multicolumn{2}{|l|}{ Alcohol History } \\
\hline Yes & $33(53.2)$ \\
\hline No & $29(46.8)$ \\
\hline \multicolumn{2}{|c|}{ Alcohol Habit (n=33) } \\
\hline Daily & $8(24.2)$ \\
\hline Social & $23(69.8)$ \\
\hline Heavy drinker & $2(6.0)$ \\
\hline \multicolumn{2}{|c|}{ Duration of Alcohol Intake ( $n=33$ ) } \\
\hline$<20$ years & $17(49.8)$ \\
\hline $20-40$ years & $16(47.2)$ \\
\hline$>40$ years & $1(3.0)$ \\
\hline \multicolumn{2}{|c|}{ Washing hands before food } \\
\hline Yes & $62(100)$ \\
\hline No & 0 \\
\hline \multicolumn{2}{|l|}{ Taking Oily food } \\
\hline Yes & $48(77.4)$ \\
\hline No & $14(22.6)$ \\
\hline \multicolumn{2}{|l|}{ Taking Spicy food } \\
\hline Yes & $46(74.2)$ \\
\hline No & $16(25.8)$ \\
\hline \multicolumn{2}{|c|}{ Taking Food on time } \\
\hline Yes & $20(32.3)$ \\
\hline No & $42(67.7)$ \\
\hline \multicolumn{2}{|c|}{ Associated Disease* } \\
\hline Yes & $13(21.0)$ \\
\hline No & $49(79.0)$ \\
\hline
\end{tabular}

spicy food whereas, $21 \%$ of the patients had associated disease along with $H$. pylori infection (Table 2).

\section{Treatment regimen and Patient Compliance}

The Standard triple drug therapy was prescribed to $50 \%$ $(n=31)$ of the patients whereas Sequential drug therapy was administered to $50 \%(n=31)$ patients on a random basis. In the Standard Triple Drug Therapy, Esomeprazole 20 mg, Clarithromycin $500 \mathrm{mg}$ and Amoxicillin 1000 mg were prescribed twice daily for 14 days whereas, in 
the Sequential Drug Therapy, Esomeprazole $20 \mathrm{mg}$ and Amoxicillin $1000 \mathrm{mg}$ were prescribed twice daily for 5 days, followed by Esomeprazole $20 \mathrm{mg}$, Clarithromycin $500 \mathrm{mg}$ and Tinidazole $500 \mathrm{mg}$ were prescribed for remaining 5 days.

The study defines a patient to be compliant if he/she never misses a dose of prescribed medications or has never discontinued medications. Among the studied population, $82.3 \%(n=51)$ of the cases were found to be compliant to the prescribed medications (fig. 1) of which $60.8 \%$ of them were males. Similarly, the forgetfulness (91\%) was found to be the main factor for the missing the medication among non-complaint patients.

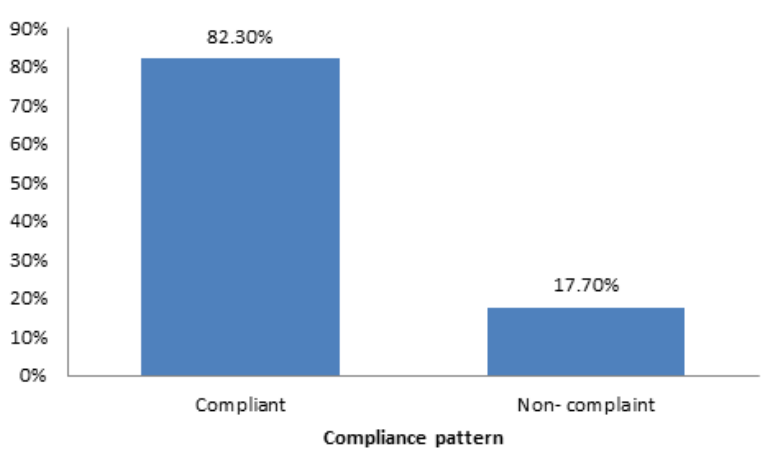

Figure 1. Compliance pattern of the patients

There are various factors affecting non-compliance in patients with $H$. pylori infection. The factors such as medications and regimens, adverse effects of the regimens, personal history of the patients, patient's knowledge about the disease and the precautions to be taken during the period of therapy and doctor- patient's relationships may influence the compliance. In the study, adverse effects were seen in $72.5 \%$ of the patients. The most common adverse effects reported to be taste alteration with loss of appetite $(38.7 \%)$ whereas $27.4 \%$ of the patients reported with diarrhea and $4.8 \%$ of the patients had vomiting and one patient had reported of increased appetite. Among the 11 non-compliant patients, 8 of them had experienced adverse effects (Table 3).

Of the total compliant patients, $84.4 \%(n=43)$ patients had knowledge about the precautions to be taken during the period of therapy while $15.6 \%(n=8)$ lacked such knowledge. Of the total non-compliant patients, $54.5 \%(n=6)$ continued smoking cigarette during the period of therapy and $63.6 \%$ $(n=7)$ of them consumed alcohol during the therapy period. Nevertheless, no association was found between the compliance, patients knowledge about the precautions to be taken during the therapy and smoking and alcohol intake during the therapy (Table 3).

Of the total non-compliant patients, $45.4 \%(n=5)$ of the patients were below the age of 30 years whereas $36.4 \%$ $(n=4)$ were between the age of 30 to 60 years and $18.2 \%$ $(n=2)$ of them were above 60 years of age. Likewise, those among non-compliant patients, $81.8 \%(n=9)$ were males
Table 3. Relation of Demographic and Personal History with regards to Compliance.

\begin{tabular}{|c|c|c|c|c|}
\hline Characteristics & $\begin{array}{l}\text { No. of } \\
\text { Patients(\%) }\end{array}$ & $\begin{array}{l}\text { Compliant } \\
n=51(\%)\end{array}$ & $\begin{array}{l}\text { Non-compliant } \\
\mathrm{n}=11 \text { (\%) }\end{array}$ & $\begin{array}{l}p \\
\text { value }\end{array}$ \\
\hline \multicolumn{5}{|l|}{ Age } \\
\hline$<30$ & $16(25.8)$ & $11(21.6)$ & $5(45.4)$ & \\
\hline $30-60$ & $38(61.3)$ & $34(66.6)$ & $4(36.4)$ & 0.17 \\
\hline$>60$ & $8(12.9)$ & $6(11.8)$ & $2(18.2)$ & \\
\hline \multicolumn{5}{|l|}{ Gender } \\
\hline Male & $40(64.5)$ & $31(60.8)$ & $9(81.8)$ & \\
\hline Female & $22(35.5)$ & $20(39.2)$ & $2(18.2)$ & 0.16 \\
\hline \multicolumn{5}{|l|}{ Literacy } \\
\hline Literate & 39 (62.9) & $30(58.8)$ & $9(81.8)$ & \\
\hline Illiterate & $23(37.1)$ & $21(41.2)$ & $2(18.2)$ & 0.13 \\
\hline \multicolumn{5}{|c|}{ Treatment Regimen } \\
\hline $\begin{array}{l}\text { Triple Drug } \\
\text { Therapy }\end{array}$ & $31(50)$ & $26(51.0)$ & $5(45.4)$ & \\
\hline $\begin{array}{r}\text { Sequential } \\
\text { Drug Therapy }\end{array}$ & $31(50)$ & $25(49.0)$ & $6(54.6)$ & 0.73 \\
\hline \multicolumn{5}{|l|}{ Adverse Effects } \\
\hline Yes & $45(72.5)$ & $37(72.6)$ & $8(72.7)$ & \\
\hline No & $17(27.5)$ & $14(27.4)$ & $3(27.3)$ & 0.99 \\
\hline \multicolumn{5}{|c|}{ Instruction by Physician } \\
\hline Yes & $26(42)$ & $22(42.9)$ & $4(36.3)$ & \\
\hline No & $36(58)$ & $29(57.1)$ & $7(63.7)$ & 0.67 \\
\hline \multicolumn{5}{|c|}{ Knowledge about precautions } \\
\hline Yes & $51(82.2)$ & $43(84.4)$ & $8(72.7)$ & \\
\hline No & $11(17.8)$ & $8(15.6)$ & $3(27.3)$ & 0.38 \\
\hline \multicolumn{5}{|l|}{ Self-medication } \\
\hline Yes & $57(78.1)$ & $47(92.2)$ & $10(91.0)$ & \\
\hline No & $5(21.9)$ & $4(7.8)$ & $1(9.0)$ & 0.89 \\
\hline \multicolumn{5}{|c|}{ Smoking during therapy } \\
\hline Yes & $34(54.8)$ & $27(53.0)$ & $6(54.5)$ & \\
\hline No & $28(45.2)$ & $24(47.0)$ & $5(45.5)$ & 0.92 \\
\hline \multicolumn{5}{|c|}{ Alcohol during therapy } \\
\hline Yes & $33(53.2)$ & $26(51.0)$ & $7(63.6)$ & \\
\hline No & $29(46.8)$ & $25(49.0)$ & $4(36.4)$ & 0.44 \\
\hline
\end{tabular}

and $18.2 \%(n=2)$ were females. Similarly, $81.8 \%(n=9)$ of the non-complaint patients were literate whereas $18.2 \%(n=6)$ of them were illiterate. However, there was no significant association between compliance, age, gender and literacy among the patients. (Table 3)

Of the total non-compliant patients, $63.7 \%(n=7)$ of them complained of lack of proper instructions about the disease and prescribed regimen from their treating physician. Likewise, those among non-compliant patients, 54.6\% $(n=6)$ of them were under Sequential drug therapy whereas $45.5 \%$ $(n=5)$ of the non-compliant patients were under standard triple drug therapy. However, there was no significant association between compliance and instructions provided by the treating physician and the treatment regimen (Table 
3). In this study, $91 \%(n=10)$ of the non-compliant patients took medicines by themselves while only $9 \%(n=1)$ of them received support from their family members or others for taking the prescribed medicines. However, there was no significant association between compliance and family and social support. (Table 3)

\section{Efficacy pattern}

The study defines efficacy as the ability of a drug to achieve the desired effect i.e. to eradicate the $H$. pylori infection. In this study, among 31 patients prescribed with Standard Triple drug regimen, efficacy produced was 58\% $(n=18)$ of the patients whereas among 31 patients prescribed with Sequential drug therapy, efficacy was seen in $51.6 \%$ ( $n=16$ ) of the patients. However, there was no significant association between efficacy produced by Standard Triple drug therapy and Sequential drug therapy (Table 4). Further, comparing the eradication rate in terms of stool antigen test, 34 patients showed negative antigen stool test while 28 patients showed positive test result with antigen stool test. The results of stool antigen test repeated five weeks after the completion of standard triple drug regimen and Sequential drug regimens.

Table 4. Efficacy Pattern of Standard Triple Drug therapy and Sequential Drug therapy $(\mathrm{N}=62)$

\begin{tabular}{|c|c|c|}
\hline Treatment Regimen & No. of patients (\%) & $p$ value \\
\hline \multicolumn{3}{|l|}{ Triple Drug Therapy } \\
\hline Eradicated (efficacious) & $18(58.0)$ & \multirow[t]{2}{*}{0.29} \\
\hline Not-Eradicated (not efficacious) & $13(42.0)$ & \\
\hline \multicolumn{3}{|l|}{ Sequential Drug Therapy } \\
\hline Eradicated (efficacious) & $16(51.6)$ & \multirow[t]{2}{*}{0.3} \\
\hline Not-Eradicated (not efficacious) & $15(48.4)$ & \\
\hline
\end{tabular}

\section{Factors affecting efficacy}

In this study, the treatment regimen showed effective in more than half of the patients and did not showed relation with the age factor as well as with the patient literacy level in terms of efficacy of the treatment (Table $5)$. Among the patients who showed good efficacy to the treatment regimen $(n=34)$, most of them $(53 \%)$ were under Standard Triple drug therapy (Table 5) though, there was no significant difference between Standard Triple drug therapy and Sequential Drug Therapy in terms of efficacy. Similarly, there was no significant association between efficacy and personal habits of the patients as well (Table 5). However, compliance to the therapy or the prescribed medication showed a significant relation $(p<0.05)$ with the efficacy (Table 5).

\section{DISCUSSION}

Though, H. pylori infected people have no symptoms, it is capable of causing a number of digestive problems including ulcers and even stomach cancer. It is usually
Table 5. Relation of various factors in terms of efficacy ( $N=62$ )

\begin{tabular}{|c|c|c|c|c|}
\hline Characteristics & $\begin{array}{l}\text { No. of } \\
\text { Patients (\%) }\end{array}$ & $\begin{array}{l}\text { Efficacious } \\
n=34(\%)\end{array}$ & $\begin{array}{l}\text { Non- } \\
\text { efficacious } \\
n=28(\%)\end{array}$ & $\begin{array}{l}p \\
\text { value }\end{array}$ \\
\hline \multicolumn{5}{|l|}{ Age } \\
\hline$<30$ & $16(25.8)$ & $11(21.6)$ & $5(45.4)$ & \\
\hline $30-60$ & $38(61.3)$ & $34(66.6)$ & $4(36.4)$ & 0.17 \\
\hline$>60$ & $8(12.9)$ & $6(11.8)$ & $2(18.2)$ & \\
\hline \multicolumn{5}{|l|}{ Gender } \\
\hline Male & $40(64.5)$ & $31(60.8)$ & $9(81.8)$ & \\
\hline Female & $22(35.5)$ & $20(39.2)$ & $2(18.2)$ & 0.16 \\
\hline \multicolumn{5}{|l|}{ Literacy } \\
\hline Literate & 39 (62.9) & $30(58.80$ & $9(81.8)$ & \\
\hline Illiterate & $23(37.1)$ & $21(41.2)$ & $2(18.2)$ & 0.13 \\
\hline \multicolumn{5}{|c|}{ Treatment Regimen } \\
\hline $\begin{array}{l}\text { Triple Drug } \\
\text { Therapy }\end{array}$ & $31(50)$ & $26(51.0)$ & $5(45.4)$ & \\
\hline $\begin{array}{r}\text { Sequential } \\
\text { Drug Therapy }\end{array}$ & $31(50)$ & $25(49.0)$ & $6(54.6)$ & 0.73 \\
\hline \multicolumn{5}{|l|}{ Adverse Effects } \\
\hline Yes & $45(72.5)$ & $37(72.6)$ & $8(72.7)$ & \\
\hline No & $17(27.5)$ & $14(27.4)$ & $3(27.3)$ & 0.99 \\
\hline \multicolumn{5}{|c|}{ Instruction by Physician } \\
\hline Yes & $26(42)$ & $22(42.9)$ & $4(36.3)$ & \\
\hline No & $36(58)$ & $29(57.1)$ & $7(63.7)$ & 0.67 \\
\hline \multicolumn{5}{|c|}{ Knowledge about precautions } \\
\hline Yes & $51(82.2)$ & $43(84.4)$ & $8(72.7)$ & \\
\hline No & $11(17.8)$ & $8(15.6)$ & $3(27.3)$ & 0.38 \\
\hline \multicolumn{5}{|l|}{ Sel-medication } \\
\hline Yes & $57(78.1)$ & $47(92.2)$ & $10(91.0)$ & \\
\hline No & $5(21.9)$ & $4(7.8)$ & $1(9.0)$ & 0.89 \\
\hline \multicolumn{5}{|c|}{ Smoking during therapy } \\
\hline Yes & $34(54.8)$ & $27(53.0)$ & $6(54.5)$ & \\
\hline No & $28(45.2)$ & $24(47.0)$ & $5(45.5)$ & 0.92 \\
\hline \multicolumn{5}{|c|}{ Alcohol during therapy } \\
\hline Yes & $33(53.2)$ & $26(51.0)$ & $7(63.6)$ & \\
\hline No & $29(46.8)$ & $25(49.0)$ & $4(36.4)$ & 0.44 \\
\hline \multicolumn{5}{|l|}{ Compliance } \\
\hline Compliant & $51(82.2)$ & $31(91.2)$ & $20(71.5)$ & \\
\hline $\begin{array}{l}\text { Non-com- } \\
\text { pliant }\end{array}$ & $11(17.7)$ & $3(8.8)$ & $8(28.5)$ & 0.04 \\
\hline \multicolumn{5}{|c|}{ Taking oily food during treatment } \\
\hline Yes & $48(77.4)$ & $26(76.5)$ & $22(78.5)$ & \\
\hline No & $14(22.6)$ & $8(23.5)$ & $6(21.5)$ & 0.84 \\
\hline \multicolumn{5}{|c|}{ Taking Spicy food during treatment } \\
\hline Yes & $46(74.2)$ & $27(79.4)$ & $19(67.8)$ & \\
\hline No & $16(25.8)$ & 7 (20.6) & $9(32.2)$ & 0.3 \\
\hline
\end{tabular}

caused by consuming food and water contaminated with fecal matter. No single drug cures $H$. pylori infection. Most treatment regimens involve taking several medications for 14 days. 
In the present study, comparative clinical efficacy of sequential drug therapy and standard triple drug therapy in the eradication of $H$. pylori in gastritis patient was attempted by repeating stool antigen test after five weeks of completing of the regimen.

The main objective of this study was to assess the efficacy of sequential drug therapy in the eradication of $H$. pylori in gastritis with respect to the standard triple drug therapy. The present study showed higher $H$. pylori infection in males than in females. However, the cause of male predominance on this study was not clear except that the number of male patient were more in this study. The result was consistent with several studies conducted in Nepal and several other developing countries where higher numbers of male patients were infected with $H$. pylori infection compared to females. ${ }^{20-22}$ Similarly, other study done at Dhulikhel Hospital, among 224 patients, showed the similar result. ${ }^{20}$ The lower number of females with $H$. pylori infection might be due antimicrobials used for many other illnesses as suggested by previous study. ${ }^{21}$ This explanation was in consistent with another study in which women consumed $17 \%$ more antibiotics than men. ${ }^{22}$ However, in another study, they reported higher rate of infection in females than in males suggesting the hormones in their dominance. $^{23}$

In this study, a majority of the patients belonged to middleaged adult group followed by patients belonging to young adults. This could be due to acquisition of $H$. pylori being common in the childhood and increasing to adulthood as the patient reaches to that age group. The reason for lowest number of elderly patients with $H$. pylori infection based on this study is suggestive of decrease in infection with age which may be probably due to the development of unfavorable gastric environment with the advance age as suggested by another study. ${ }^{24}$ Similarly, other study has explained the lower number of $H$. pylori infection in the elderly, the reason being that $H$. pylori could have been present in a small number or low activation which might not have been detected..$^{23}$ They also suggested that $H$. pylori could have been present in the past, but was eliminated on account of the development of an unfavorable gastric environment with age. This study showed that majority of the patients acquired persistent infection throughout the adulthood which was comparable with a number of other studies in which almost $30-50 \%$ of $H$. pylori infection was found to occur in early childhood which increased to $90 \%$ by the time the patient reached adulthood..$^{25,26}$

Good patient compliance is also a vital predictor of outcome. $^{5}$ Therefore, it is important to emphasize its relevance to patient. Poor compliance not only contributes to antibiotic resistance, but patients who do not complete their full course of antibiotics are also more likely to fail treatment.

In this study, majority of patients were compliant to the prescribed medication which was similar to the result obtained by one of the previous study. ${ }^{27}$ Higher compliant rate has been found among those patients with acute conditions of $H$. pylori infection compared to those with other associated chronic diseases such as Hypertension, Diabetes, Ischemic Heart Disease (IHD), Bronchial asthma, Chronic Obstructive Pulmonary Disease (COPD) etc. ${ }^{28-30}$ The most important factor which might have helped the patients to be complaint to two prescribed regimen in the present study might be the two weeks duration of treatment regimen. In addition, higher compliance among the patients with $H$. pylori infection in this study might be due to the fact that a majority of them were literate, which might have helped them to understand the instructions to take the prescribed medication given by the treating physician. The better compliance is achieved with more circumscribed regimen as well as situations in which patients have greater resources such as education and income as stated in one of the study done in California. ${ }^{27}$ The health literacy of the patient might have enabled them to understand basic health information and services needed to make appropriate health decisions as suggested by another study. ${ }^{31}$

In the present study, only in a few numbers of patients, non-complaint to medication was seen. A majority of the non-compliant patients had missed the dose due to forgetfulness. The onset of adverse effects such as diarrhea, taste alteration, decrease appetite, vomiting, increased appetite and dizziness was additional reason for missing the dose as reported by few number of non- complaint patients which coincided with the result obtained by Lefebvre et al, who found onset of adverse effects such as nausea, stomach pain and bad taste, in the treatment of $H$. pylori infection leading to poor compliance. ${ }^{18}$ Forgetfulness was reported as one of the major reasons for missing dose not just in acute conditions like $H$. pylori infection but in different chronic diseases such as those in type II diabetes mellitus and COPD. ${ }^{29}$

The study showed that a higher number of males were more compliant to medication as compared to females which was in accordance with the study done in Arctic Canada in the treatment of $H$. pylori infection. ${ }^{18}$ The lesser number of females being compliant might be due to the fact that they spent less time and energy taking care of them as they are frequently the primary care giver to their family members as mentioned by the study done by Sharon et al. ${ }^{32}$ However, no statistically significant association was found between gender and compliance to medication. Similarly, other study done on COPD patients, where no relationship was found between gender and compliance to the therapy. ${ }^{29}$ A previous study has found that patients who were more likely to be non-compliant were during later years of life (60-70 years) and in children compared to adults. ${ }^{18,29}$ On contrary to the findings from previous studies, in this study, a similar proportion of complaint and non-compliant individuals fell under the middle-aged adult group. This might be due to the fact that a majority 
of the individuals under this study belonged to the same age group. Further, a high literacy rate among the patients under this study and higher number of patients with the knowledge about the precaution to be taken during medication might have led to higher compliance in this age group. However, there was no statistically significant association between patient's compliance to medication and age.

Among the patients in whom adverse effects of medicine were seen, majority of them reported of gastrointestinal discomfort (vomiting, diarrhea, increased appetite and decreased appetite) along with the taste alteration and dizziness. Consistent with this findings, previous survey have found that majority of patients on $H$. pylori therapy reported of gastrointestinal disorders with abnormal taste. $^{26}$ These adverse effects are bothersome but the patient is more likely to tolerate those mild effects if they are clear about the goal of the therapy. ${ }^{33}$ These results also correspond to the findings from another study in which they reported that the appearance of side effects affected compliance to the medication in patients with COPD. ${ }^{29}$ Non-compliance to medication due to the occurrences of adverse effects has been seen in patients with type II diabetes mellitus, hypertension and in HIV positive patients. ${ }^{34-37}$

This study shows that the majority of patients were compliant to the standard triple drug regimen than to the sequential drug regimen. Among the participants who were reported to be non-complaint to the medication, the following barriers to treatment were reported: consumption of alcohol and smoking during therapy, forgetfulness and the various other adverse effects. It might also be possible that the patient might think that they were not getting any benefit from the medication or might feel asymptomatic or may get fed up from their use due to their adverse effects like metallic taste and nausea, and do not feel their importance. One of the studies have found the similar result, which reported that $67 \%$ of the patients were complaint to standard triple drug therapy and $62 \%$ were to sequential drug therapy, and forgetfulness, changing mind about taking medicine, alcohol consumption, stomach pain and nausea as a reason for the non-compliance to the regimen. ${ }^{18}$ So, similar pattern was found in this study, however no significant difference was found between the compliance pattern between the two regimens.

In this study, as majority of the patient belonged to the middle-age adult group, in whom the therapy was efficacious and among them, the group of male patients showed regimen to be more efficacious. The reason for therapy to be efficacious among this age group of patients was probably because majority of the patient in this study belonged to that age group. This study showed that the regimen was not efficacious on majority of the patient who had continued smoking during the therapy which may predict the failure of efficacy of the regimen.
To explain the better performance of treatment in nonsmoker vs. smokers, it has been hypothesized that smoking may induce a decrease in gastric blood flow and mucus secretion, and therefore reduce the efficacy of treatment by reducing the delivery of the antibiotics to the gastric mucosa. ${ }^{38}$ Similar result was obtained from previous study, which showed that cigarette smoking caused significant reduction in gastric mucosal blood flow in the antrum (34\%) and in the corpus (33\%). ${ }^{39}$ In this study, it was found that those patients who were not compliant to the prescribed medication were not efficacious to the therapy. There was significant association between compliance to the therapy and efficacy. Despite well-established efficacy of $H$. pylori treatment regimens in the clinical trials, in the eradication of $H$. pylori infection; non-compliance to treatment is a major obstacle to their effectiveness in clinical practice which was consistent to this study. Irregular drug intake and treatment discontinuation have been associated with a greater risk of therapeutic failure.

In the present study, among the patients with $H$. pylori infection, the efficacy of standard triple drug therapy was reported to be more than that of sequential drug therapy. However, there was no significant difference in the efficacy of the two regimens, concluding that both the regimens are equally efficacious in the treatment of $H$. pylori infection. Similarly, $H$. pylori eradication obtained with standard triple drug regimen was more than that with sequential drug regimen in the present study. However, this study did not show any significant difference in the eradication of $H$. pylori infection with the two regimens. Supporting this result, other study has also highlighted that there was no significant difference between eradication rate achieved with the standard triple drug regimen (66.4\%) and the sequential drug regimen (72.1\%). ${ }^{40}$ These findings challenge the recommendations of systemic reviews based primarily on data from Italy that showed sequential therapy is more effective than standard triple therapy in eradication of $H$. pylori infection. ${ }^{6,12,41}$ Recent study has reported eradication rates of $87 \%$ in Taiwanese patients with $H$. pylori infection who received 10 days regimen of sequential therapy. ${ }^{38}$ The response rate was significantly higher than that in this study. In the same study, extending the duration of treatment with sequential therapy to 14 days resulted in a further $3-4 \%$ increase in eradication rates. ${ }^{38}$ Moreover, a 14 days sequential regimen was associated with significantly higher eradication rate than achieved with a 14 days standard triple therapy regimen. Although a 14 days sequential regimen was not investigated in this study, it is unlikely that additional improvement would be seen because of the very limited efficacy seen in the present study after 10 days of sequential drug therapy.

The result of this study demonstrated that $H$. pylori eradication rates were similar for both the treatment groups. No significant difference in eradication rates was found between the two groups. It might be due to small sample size and due to resistance to antibiotics. 
Recent evidence also showed no significant difference in eradication rates in standard triple drug therapy (87.8\%) and sequential drug therapy (89.6\%) concluding that both the regimens were equally effective. ${ }^{42}$

Several studies in the literature have shown that the effectiveness of the standard triple drug therapy has been declining over the past years, mainly due to clarithromycin resistance, especially in the USA and Europe. ${ }^{43-45}$ For this reason, sequential therapy has been assessed, with eradication rates greater than $90 \%$ as study conducted previously. ${ }^{34}$ In the view of this result, sequential therapy has been recommended as the preferred treatment to eradicate $H$. pylori, especially in Europe. Unlike studies from other countries, present study has not shown significant difference in the eradication rates between the two regimens. As previously mentioned, resistance to antibiotics, especially clarithromycin, is the main reason for the decrease in $H$. pylori eradication rates. However, it is important to know that this resistance varies from country to country and from region to region in the same country. ${ }^{46,47}$ This variation in resistance can influence the efficacy of $H$. pylori regimens. Most of the studies have also found the similar results which correlate with the present study. ${ }^{48,49}$

Several studies have shown that stool antigen test have very reliable results particularly in adult patients as a non-invasive method. The major advantage of this test is the cost and the possibility of being performed in any laboratory and it can be used to diagnose the infection and confirm that it has been cured after treatment. This study has shown stool antigen to be negative in majority of the patients, after repeating the test five weeks after completion of both regimens, indicating the eradication of $H$. pylori infection. Similarly, sensitivity of stool antigen test was more than histopathologic test in present study, which was consistent with the previous study, where the sensitivity of stool antigen test was high i.e. $90 \%$ for the detection of $H$. pylori infection. Likewise, study done in 4769 patients, sensitivity of stool antigen test was $92.45 \%$ and in another study done in 2078 patients, sensitivity was $88.35 \%$ respectively. ${ }^{50,51}$ Unlike histopathologic test for detection of $H$. pylori, accuracy of stool antigen test in diagnosis of $H$. pylori is high and also an accurate method to confirm $H$. pylori eradication after completion of the

\section{REFERENCES}

1. Suerbaum S, Michetti P. Helicobacter pylori infection. New England Journal of Medicine. 2002;347(15):1175-86.

2. Longo DL, Fauci AS, Kasper DL, Hauser SL, Jameson JL, Loscalzo J. Harrison's principles of internal medicine 18 ed. Vol. 2 EB: McGraw Hill Professional; 2012.

3. Morris Brown L. Helicobacter pylori: epidemiology and routes of transmission. Epidemiol Rev. 2000;22(2):283-97.

4. Hunt R, Xiao S, Megraud F, Leon-Barua R, Bazzoli F, Van der Merwe $S$, et al. Helicobacter pylori in developing countries. World gastroenterology organisation global guideline. J Gastrointestin Liver Dis. 2011;20(3):299-304. therapy. It has several distinct and significant advantages over other invasive diagnosis as: 1) they are simple to administer 2) their costs are considerably low, and 3) they can be done in any laboratory. Importantly, stool specimen can be obtained with relative ease from the patients who are unlikely to cooperate for endoscopy for taking biopsy sample. ${ }^{51}$ These features make $H$. Pylori stool antigen assays particularly appealing for children and reluctant patients for diagnosing the disease and evaluation of eradication therapy. Nevertheless, the current study has following limitations:

1. Due to expensive cost and difficult invasive procedure of endoscopy, repeat histopathological biopsy test for monitoring the response to treatment was not done.

2. We have not assessed $H$. pylori resistance to antibiotics through culture and sensitivity tests, since it is difficult test to perform in our community and, when available, it is still very costly for the patient.

However, the current study has been successful in providing insight in the treatment protocol and patient adherence during $H$. pylori infection. The finding of this study will need to be reinforced and replicated with larger sample size to evaluate the eradication rates of two regimens. Moreover, further studies and new trails are needed to assess and confirm the tendency of $H$. pylori to increase its resistance to clarithromycin in our community, which will improve the outcomes to the treatment regimen.

\section{CONCLUSION}

In conclusion, our findings suggest that sequential therapy has not proven to be superior over triple drug therapy in eradicating $H$. pylori infection. Since it has satisfactory eradication rates and less complexity for the patient, triple therapy is still good first-line regimen to eradicate the $H$. pylori infection. Though histopathological test has been used as an invasive diagnostic test for detection of $H$. pylori infection, stool antigen test can be preferred as a non-invasive test, particularly in selection of the cases requiring endoscopic examination, for diagnosis of $H$. pylori infection, monitoring the response to treatment and in epidemiological studies, as stool antigen test has high sensitivity as compared to histopathological test.

5. Chey WD, Wong BC, Gastroenterology PPCotACo. American College of Gastroenterology guideline on the management of Helicobacter pylori infection. American Journal of Gastroenterology. 2007;102(8):1808-25.

6. Malfertheiner P, Megraud F, O'morain C, Hungin A, Jones R, Axon A, et al. Current concepts in the management of Helicobacter pylori infection- The Maastricht 2-2000 Consensus Report. Alimentary pharmacology \& therapeutics. 2002;16(2):167-80.

7. Malfertheiner P, Megraud F, O'Morain C, Bazzoli F, El-Omar E, Graham $D$, et al. Current concepts in the management of Helicobacter pylori infection: the Maastricht III Consensus Report. Gut. 2007;56(6): 77281. 
8. Fock KM, Katelaris P, Sugano K, Ang TL, Hunt R, Talley NJ, et al. Second Asia-Pacific consensus guidelines for helicobacter pylori infection. Journal of gastroenterology and hepatology. 2009;24(10):1587-600.

9. Malfertheiner P, Megraud F, O'Morain CA, Atherton J, Axon AT, Bazzoli $F$, et al. Management of Helicobacter pylori infection-the Maastricht IV/Florence consensus report. Gut. 2012;61(5):646-64.

10. Horvath A, Dziechciarz P, Szajewska H. Meta-analysis: sequential therapy for $\mathrm{H}$ elicobacter pylori eradication in children. Alimentary pharmacology \& therapeutics. 2012;36(6):534-41.

11. Kim BG, Lee DH, Ye BD, Lee KH, Kim BW, Kim SG, et al. Comparison of 7-day and 14-day proton pump inhibitor-containing triple therapy for Helicobacter pylori eradication: neither treatment duration provides acceptable eradication rate in Korea. Helicobacter. 2007;12(1):31-5.

12. Zullo A, De Francesco V, Hassan C, Morini S, Vaira D. The sequential therapy regimen for Helicobacter pylori eradication: a pooled-data analysis. Gut. 2007;56(10):1353-7.

13. Choi HS, Chun HJ, Park SH, Keum B, Seo YS, Kim YS, et al. Comparison of sequential and 7-, 10-, 14-d triple therapy for Helicobacter pylori infection. World journal of gastroenterology: WJG. 2012;18(19):2377.

14. Gatta L, Vakil N, Leandro G, Di Mario F, Vaira D. Sequential Therapy or Triple Therapy forHelicobacter pylorilnfection: Systematic Review and Meta-Analysis of Randomized Controlled Trials in Adults and Children. American Journal of Gastroenterology. 2009;104(12):306979.

15. Malfertheiner $P$, Selgrad M. Helicobacter pylori infection and current clinical areas of contention. Current opinion in gastroenterology. 2010;26(6):618-23.

16. Zullo A, De Francesco V, Hassan C, Panella C, Morini S, lerardi E. Secondline treatment for Helicobacter pylori eradication after sequential therapy failure: a pilot study. Clinical Practice. 2006;3(2):251.

17. Megraud F. H pylori antibiotic resistance: prevalence, importance, and advances in testing. Gut. 2004;53(9):1374-84.

18. Lefebvre M, Chang H-J, Morse A, van Zanten SV, Goodman KJ, Group $\mathrm{CHW}$. Adherence and barriers to H. pylori treatment in Arctic Canada. International journal of circumpolar health. 2013;72(1):22791.

19. Al-Eidan F, McElnay J, Scott M, McConnell J. Management of Helicobacter pylori eradication-the influence of structured counselling and follow-up. British journal of clinical pharmacology. 2002;53(2):163-71.

20. Makaju R, Tamang M, Sharma Y, Sharma N, Koju R, Ashraf M. Prevalence of helicobacter pylori in Dhulikhel Hospital, Kathmandu University Teaching Hospital: A retrospective histopathologic study. Kathmandu Univ Med J (KUMJ). 2005;3:355-9.

21. Luknarova N, Slezakova M, Blahutova A. Antibiotic consumption in relation to sex and age. Ceskoslovenska farmacie. 1992;41(4-5):162.

22. Patrick DM, Marra F, Hutchinson J, Monnet DL, Ng H, Bowie WR. Per capita antibiotic consumption: how does a North American jurisdiction compare with Europe? Clinical Infectious Diseases. 2004;39(1):11-7.

23. Zhu Y, Zhou X, Wu J, Su J, Zhang G. Risk factors and prevalence of Helicobacter pylori infection in persistent high incidence area of gastric carcinoma in Yangzhong city. Gastroenterology research and practice. 2014;2014.

24. Murray LJ, McCRUM EE, Evans AE, Bamford KB. Epidemiology of Helicobacter pylori infection among 4742 randomly selected subjects from Northern Ireland. International journal of epidemiology. 1997;26(4):880-7.

25. Frenck Jr RW, Clemens J. Helicobacter in the developing world. Microbes and infection. 2003;5(8):705-13.

26. Abbasinazari M, Sahraee Z, Mirahmadi M. The Patients' Adherence and Adverse Drug Reactions (ADRs) which are caused by Helicobacter pylori eradication regimens. Journal of Clinical and Diagnostic Research: JCDR. 2013;7(3):462
27. DiMatteo MR. Variations in patients' adherence to medical recommendations: a quantitative review of 50 years of research. Medical care. 2004:200-9.

28. Shrestha R, Pant A, Shrestha SS, Shrestha B, Gurung R, Karmacharya B. A cross-sectional study of medication adherence pattern and factors affecting the adherence in chronic obstructive pulmonary disease. Kathmandu Univ Med J (KUMJ). 2015;13(1):64-70.

29. Shrestha SS, Shakya R, Karmacharya B, Thapa P. Medication adherence to oral hypoglycemic agents among type II diabetic patients and their clinical outcomes with special reference to fasting blood glucose and glycosylated hemoglobin levels. Kathmandu Univ Med J (KUMJ). 2013;11(3):226-32.

30. Ahmad NS, Ramli A, Islahudin F, Paraidathathu T. Medication adherence in patients with type 2 diabetes mellitus treated at primary health clinics in Malaysia. Patient preference and adherence. 2013;7:525

31. Kocurek B. Promoting medication adherence in older adults and the rest of us. Diabetes Spectrum. 2009;22(2):80-4.

32. Rolnick SJ, Pawloski PA, Hedblom BD, Asche SE, Bruzek RJ. Patient characteristics associated with medication adherence. Clinical medicine \& research. 2013;11(2):54-65.

33. O'Connor JPA, Taneike I, O'Morain C. Improving compliance with Helicobacter pylori eradication therapy: when and how? Therapeutic advances in gastroenterology. 2009;2(5):273-9.

34. Vaira D, Zullo A, Vakil N, Gatta L, Ricci C, Perna F, et al. Sequential therapy versus standard triple-drug therapy for Helicobacter pylori eradication: a randomized trial. Annals of internal medicine. 2007;146(8):556-63.

35. Nasa M, Choksey A, Phadke A, Sawant P. Sequential therapy versus standard triple-drug therapy for Helicobacter pylori eradication: a randomized study. Indian Journal of Gastroenterology. 2013;32(6):392-6.

36. Monroe AK, Rowe TL, Moore RD, Chander G. Medication adherence in HIV-positive patients with diabetes or hypertension: a focus group study. BMC health services research. 2013;13(1):1-7.

37. Seddik H, Ahid S, El Adioui T, El Hamdi F-Z, Hassar M, Abouqal R, et al. Sequential therapy versus standard triple-drug therapy for Helicobacter pylori eradication: a prospective randomized study. European journal of clinical pharmacology. 2013;69(9):1709-15.

38. Liou J-M, Chen $C-C$, Chen $M-J$, Chen $C-C$, Chang $C-Y$, Fang $Y-J$, et al. Sequential versus triple therapy for the first-line treatment of Helicobacter pylori: a multicentre, open-label, randomised trial. The Lancet. 2013;381(9862):205-13.

39. Iwao T, Toyonaga A, Ikegami M, Oho K, Sumino M, Sakaki M, et al. Gastric mucosal blood flow after smoking in healthy human beings assessed by laser Doppler flowmetry. Gastrointestinal endoscopy. 1993;39(3):400-3.

40. Zhou L, Zhang J, Chen M, Hou X, Li Z, Song Z, et al. A comparative study of sequential therapy and standard triple therapy forHelicobacter pyloriinfection: a randomized multicenter trial. American Journal of Gastroenterology. 2014;109(4):535-41.

41. Zsikla V, Hailemariam S, Baumann M, Mund MT, Schaub N, Meier R, et al. Increased rate of Helicobacter pylori infection detected by PCR in biopsies with chronic gastritis. The American journal of surgical pathology. 2006;30(2):242-8.

42. Eisig JN, Navarro-Rodriguez T, Teixeira ACS, Silva FM, Mattar R, Chinzon D, et al. Standard triple therapy versus sequential therapy in Helicobacter pylori eradication: a double-blind, randomized, and controlled trial. Gastroenterology Research and Practice. 2015;2015.

43. O'Connor A, Vaira D, Gisbert JP, O'Morain C. Treatment of Helicobacter pylori infection 2014. Helicobacter. 2014;19:38-45.

44. Vakil N, Lanza F, Schwartz H, Barth J. Seven-day therapy for Helicobacter pylori in the United States. Alimentary pharmacology \& therapeutics. 2004;20(1):99-107. 
45. Duck WM, Sobel J, Pruckler JM, Song Q, Swerdlow D, Friedman C, et al. Antimicrobial resistance incidence and risk factors among Helicobacter pylori infected persons, United States. Emerging infectious diseases. 2004;10(6):1088.

46. Vakil N. Are there geographic/regional differences in Helicobacter pylori eradication? Helicobactor pylori: Springer; 2003. p. 439-43.

47. Buzás GM, Lotz G, Kiss A. The Hungarian epidemiology of clarithromycin resistance in Helicobacter pylori infection. Orvosi hetilap. 2007;148(31):1461-7.

48. Greenberg ER, Anderson GL, Morgan DR, Torres J, Chey WD, Bravo LE, et al. 14-day triple, 5-day concomitant, and 10-day sequential therapies for Helicobacter pylori infection in seven Latin American sites: a randomised trial. The Lancet. 2011;378(9790):507-14.
49. Yep-Gamarra V, Rodriguez-Ulloa C, Díaz-Vélez C, Aldave-Herrera A, Donet JA, Rodas JI, et al. Sequential Versus Triple Standard Therapy for Helicobacter pylori Eradication. Gastroenterology. 2013;144(5):S333.

50. Vaira D, Vakil N, Menegatti M, van't Hoff B, Ricci C, Gatta L, et al. The stool antigen test for detection of Helicobacter pylori after eradication therapy. Annals of internal medicine. 2002;136(4):280-7.

51. Konstantopoulos N, Rüssmann H, Tasch C, Sauerwald T, Demmelmair $\mathrm{H}$, Autenrieth I, et al. Evaluation of the Helicobacter pylori stool antigen test (HpSA) for detection of Helicobacter pylori infection in children. The American journal of gastroenterology. 2001;96(3): 67783. 